\title{
Veredas
}

Revista de Estudos Linguísticos

https://periodicos.ufff.br/index.php/veredas/index

\section{A percepção e a autopercepção de professores em formação inicial sobre o ensino e a aprendizagem da leitura}

\section{The perception and the self-perception of professors in initial training on teaching and learning to read}

\author{
Lidiomar José Mascarello ${ }^{1}$, Ana Cláudia de Souza ${ }^{2}$
}

Secretaria de Estado da Educação - SC, Brasil; Universidade Federal de Santa Catarina, Brasil.

Recebido em: 08/12/2019 Aceito em: 19/05/2020

\section{RESUMO}

Esta pesquisa tem como objetivos reconhecer, compreender e discutir aspectos da percepção e da autopercepção em relação à formação inicial para a docência, no que diz respeito aos processos de ensino e de aprendizagem da leitura. Com base na literatura, considera-se que a autopercepção e a percepção da realidade podem interferir na forma de agir e na compreensão dos processos educacionais. Este é um estudo misto, bibliográfico e exploratório, do qual participaram 11 graduandos de curso de Letras-Português, que foram convidados a responder dois questionários. Os resultados indicam uma percepção positiva da realidade, mas não são generalizáveis, tendo em vista os múltiplos fatores que participam da formação profissional de professores.

\section{PALAVRAS-CHAVE:}

Percepção; autopercepção; aprendizagem da leitura; ensino da leitura; formação inicial de professores.

\begin{abstract}
This piece of research aims to recognize, understand and discuss perception and self-perception aspects regarding initial training to teach in what concerns the teaching and learning processes of reading. Based on literature, it is considered that the self-perception and the perception of the reality can interfere in the way of behaving and in the understand of the educational processes. This is a mixed study, bibliographic and exploratory, in which 11 undergraduate students of the Letter's Course took part. The participants were invited to answer two questionnaires. The results point to a positive perception of the reality, but it is not possible to generalize, once there are multiple factors participating in the professional training of teachers.
\end{abstract}

KEYWORDS:

Perception; self-perception; learning to read; teaching to read; initial teacher training.

\footnotetext{
${ }^{1}$ E-mail: lidiomarjose@gmail.com |ORCID: https://orcid.org/0000-0003-0603-3455.

${ }^{2}$ E-mail: ana.claudia.souza@ufsc.br |ORCID: https://orcid.org/0000-0002-0833-6903.
} 


\section{Introdução e compreensão do fenômeno investigado}

É comum, na introdução de uma determinada área de estudo, começar por uma definição. Embora seja um ponto de partida aceitável, se não explorado, pode ser bastante redutor. Para a palavra percepção, uma das definições encontradas indica que se trata de uma função de captação de informação dos acontecimentos do meio exterior ou interno, pela via dos mecanismos sensoriais (DORON; PAROT, 2001). Rock (1975) apresenta o conceito afirmando que o campo da percepção se situa entre o domínio dos processos sensoriais e o dos processos cognitivos.

A percepção é o ato de receber, interpretar e compreender através do psíquico ${ }^{3}$ os sinais sensoriais que provêm dos cinco sentidos presentes em nosso organismo. Por essa razão, a percepção, embora recorra ao organismo e às questões físicas, está diretamente ligada ao sistema psicológico de cada indivíduo, podendo fazer com que o resultado seja diferente em cada pessoa. Segundo Gazzaniga, Heatherton e Halpern (2018, p. 174),

[...] nossas sensação e percepção do mundo não funcionam como uma câmera ou um gravador digital, capturando fiel e passivamente as propriedades físicas dos estímulos que encontramos. Em vez disso, a nossa experiência do mundo (aquilo que vemos, ouvimos, saboreamos, cheiramos ou tocamos) resulta dos processos cerebrais que constroem ativamente as experiências perceptivas a partir da informação sensorial. Essa conversão constante da sensação em percepção permite a nossa adaptação aos detalhes dos nossos ambientes físicos.

Proveniente da palavra latina "perceptivo", que significa receber, recolher ou tomar posse de algo, a percepção é entendida pela Psicologia como o primeiro momento de um processamento cognitivo (DORON; PAROT, 2001), sendo um dos campos mais antigos dos processos fisiológicos e cognitivos estudados pela Psicologia Experimental. Na Psicologia, o estudo da percepção é de extrema importância, porque o comportamento das pessoas é baseado na interpretação que se faz da realidade e não na realidade em si. Na Psicolinguística, os estudos dos processos perceptivos vinculam-se aos estudos dos processos atencionais, estando tanto os perceptivos quanto os atencionais presentes nos processos de aquisição da linguagem e da aprendizagem de aspectos linguísticos e de modalidades linguísticas. Focalizamos, neste estudo

\footnotetext{
${ }^{3}$ O termo "psíquico" está sendo tomado aqui como a totalidade da constituição do eu, da personalidade do sujeito, abarcando, assim, os elementos cognitivos e os conhecimentos adquiridos com as experiências de vida.
} 
que ora apresentamos, os processos de ensino e aprendizagem da leitura em que a atenção e a percepção são necessárias para que a atividade ocorra com sucesso.

Segundo Chauí (1999), a tradição filosófica, até o século XX, distinguia sensação de percepção pelo grau de complexidade. Sensação e percepção são as principais formas que geram o conhecimento sensível, também chamado de conhecimento empírico ou experiência sensível. Assim, a sensação fornece as qualidades exteriores e interiores, isto é, as qualidades dos objetos e os efeitos internos dessas qualidades sobre as pessoas.

No domínio científico, foi com o nascimento da Psicologia como ciência que se verificou um impulso importante no estudo da percepção. Antes da Psicologia, contudo, o campo da percepção humana começou por ser abordado pela Filosofia. Os filósofos debruçavam-se sobre os problemas da cognição e tentavam explicar como é obtido o conhecimento do mundo (HOCHBERG, 1978). A resposta a essa questão e, por consequência, a explicação dos fenômenos perceptivos foram evoluindo ao longo do tempo, à medida que aumentava também o entendimento acerca do funcionamento do cérebro.

Para a Psicologia, a palavra "percepção" não se refere a um acontecimento isolado. Vários autores, entre os quais Sekuler e Blake (1990), descrevem-na como um processo integrado. Segundo a Psicologia, a percepção consiste em uma organização e interpretação dos estímulos que foram recebidos pelos sentidos e que possibilitam identificar certos objetos e acontecimentos. Nessa perspectiva, a percepção tem duas etapas: a sensorial e a intelectual. As duas se complementam, porque as sensações não proporcionam uma visão real do mundo e devem ser trabalhadas pelo intelecto.

Para a Filosofia, a percepção consiste em um conceito que descreve uma situação em que o espírito capta de forma intuitiva os estímulos exteriores. Diferentes pensadores e filósofos descreveram a percepção de formas distintas. Para Descartes (1988), a percepção é todo o ato de inteligência. Segundo Leibniz (2004), é um estado transitório que envolve processos múltiplos. Aqui, no presente texto, em que os objetivos se voltam para a discussão dos aspectos da percepção em relação à formação para a docência e o reconhecimento e a compreensão da percepção e autopercepção de graduandos de Letras- Português, ressaltam-se, em nossos instrumentos de coleta de dados, aspectos da autopercepção, percepção e linguagem, leitura, mediação, processos perceptivos e cognição, e a importância de cada conceito na formação inicial de professores no tocante aos processos de ensino e aprendizagem da leitura.

Um dos primeiros aspectos a serem considerados é o da autopercepção, que se refere à 
maneira pela qual as pessoas compreendem as suas próprias atitudes e crenças com base em seu comportamento em determinadas situações. Para Salvador $(1994,86)$, autoconceito se refere ao "conjunto de características, atributos, qualidades e deficiências, capacidades e limites, valores e relações que o indivíduo reconhece como descritivos de si e que percebe como dados de sua realidade". De acordo com Tonelotto e Gonçalves (2002, p.32), "um dos fatores que apresentam grau considerável de interferência na aprendizagem é a maneira pela qual os escolares se veem ou se percebem, traduzindo o conceito que têm de si mesmos". Trata-se de um fator de ordem interna e intrapessoal, capaz de interferir na aprendizagem, dificultando a realização e o alcance das metas da aprendizagem escolar. De acordo com Tonelotto (1998), o senso do eu é muito valorizado nas culturas ocidentais, dando-se à identidade e à privacidade uma grande importância durante o processo educacional e de desenvolvimento. Esse processo se inicia antes mesmo dos 18 meses de vida, quando um bebê demonstra capacidade de autorreconhecimento e, em seguida, à medida que sua linguagem se aprimora, torna-se capaz de se autodescrever, iniciando o que pode ser denominado autoconceito.

É relevante também considerarmos aqui as funções psicológicas superiores (FPS), tais como atenção, memória, imaginação, pensamento e linguagem, que são combinadas em sistemas funcionais e perceptivos, cuja finalidade é organizar adequadamente a vida mental de um indivíduo em seu meio (ROCK, 1975). A constituição das funções superiores não acontece sobre ou ao lado das funções elementares, mas a partir de complexas combinações dessas funções, mediante a elaboração de sínteses complexas. As funções superiores são, portanto, de natureza cognitivo-cultural e concebidas como transformações qualitativas que ocorrem na inter-relação entre os fatores externos e os internos, resultante da apropriação e da internalização de instrumentos e signos em um contexto de interação.

Como já mencionado anteriormente, o elemento de interação e uso de signos linguísticos colocado em evidência no estudo é a leitura. Os novos paradigmas que elucidam a questão do processo de ensino e aprendizagem da leitura são fruto de pesquisas realizadas em várias áreas do conhecimento (Linguística, Psicolinguística, Psicologia Cognitiva etc). A partir desses estudos, a leitura passou a ser vista como uma competência complexa, constituída de um conjunto de habilidades, cuja realização é dependente da relação que o leitor estabelece com o texto, a partir de determinados objetivos, em contexto específico, e também como um processo mediador de conhecimento (SOUZA; SEIMETZ-RODRIGUES; WEIRICH, 2019).

Sendo a leitura uma forma de uso da linguagem e um produto da cultura, ela se constitui 
como um processo complexo, que se desenvolve e é aprendido gradualmente, seguindo várias fases (REBELO, 1991). Para alguns pesquisadores, qualquer tipo de aprendizagem passa por três fases distintas: cognitiva, de domínio e de automatização. Na fase cognitiva, é construída uma representação global da tarefa, dos seus objetivos e da sua natureza. A fase de domínio é, sobretudo, um tempo de treino e aperfeiçoamento das operações básicas exigidas pela tarefa. A fase de automatização, a seu turno, corresponde ao momento em que deixa de existir um controle consciente para se operar com a destreza aprendida (MARTINS; NIZA, 1998).

A leitura, segundo Martins e Niza (1998), passa então por essas três fases. Na fase cognitiva, a criança constrói uma representação sobre as funções, o funcionamento e a natureza da leitura, ou seja, para que serve saber ler, como se lê, quais as características da leitura e de que forma ela se relaciona com a linguagem verbal oral. Na fase de domínio, ocorre um treino das várias operações necessárias à tarefa da leitura: reconhecimento da organização da página, dos traços das letras, estabelecimento das correspondências grafêmico-fonológicas, acesso à palavra escrita, acesso ao sentido do texto e elaboração de questionamentos, antecipação de elementos sintáticos e semânticos, memorização de informações etc. A fase de automatização corresponde ao momento em que a criança já é capaz de utilizar flexivelmente as estratégias de leitura aprendidas, sem pensar controladamente nelas (MARTINS; NIZA, 1998). Segundo Jeanne Chall (1970 apud REBELO, 1991), a maioria dos autores de diversos programas de ensino da leitura aceita como fazendo parte da definição de leitura os seguintes elementos: percepção (reconhecimento de traços e de palavras), compreensão e interpretação, apreciação e aplicação.

Tendo em vista o exposto e considerando que o estudo aqui apresentado visa reconhecer, compreender e discutir aspectos da percepção e da autopercepção quanto à formação para a docência no que concerne aos processos de ensino e de aprendizagem da leitura, tendo como objeto de análise manifestações de estudantes graduandos do Curso de Letras Língua-Portuguesa, na próxima seção deste texto, apresentamos os aspectos metodológicos da pesquisa, para, na sequência, descrever e analisar os resultados obtidos na coleta de dados associando-os a discussões teóricas.

\section{Aspectos metodológicos}

A pesquisa é resultante de um projeto propositivo híbrido do tipo bibliográfico e exploratório, em que foram considerados, especialmente, os aspectos qualitativos. Participaram 
$11^{4}$ estudantes do curso de licenciatura em Letras Português da Universidade Federal de Santa Catarina - UFSC. Todos os estudantes graduandos, matriculados em uma disciplina da licenciatura, foram convidados a participar da pesquisa de forma voluntária e assinaram o termo de consentimento livre esclarecido, que faz parte do projeto aprovado pelo Comitê de Ética e Pesquisas com Seres Humanos da UFSC, sob o Certificado de Apresentação de Apreciação Ética número 08990119.2.0000.0121, com aprovação obtida por meio do Parecer Consubstanciado 3.378.077, de 07 de junho de 2019.

Foram elaborados instrumentos para coleta de dados com o intuito de identificar aspectos perceptivos e dificuldades de aprendizagem e de compreensão de conceitos dos estudantes, professores em formação inicial. Os instrumentos utilizados nesta pesquisa foram dois questionários, sendo o primeiro relativo à autopercepção das relações interpessoais e à percepção da realidade institucional, à percepção dos estudantes sobre seus professores e à atuação no processo de ensino, e à percepção do uso do tempo para atividades acadêmicas de leitura com foco nas experiências pessoais e suas práticas de leitura. O segundo questionário investigou a percepção da formação docente e a prática e ensino de leitura, priorizando aspectos teóricos e conceituais em relação à prática de ensino e aprendizagem da leitura na formação inicial para a docência. Os estudantes responderam aos questionários em local e horário de formação acadêmica, sem prejuízos às atividades da disciplina por meio da qual os dados foram coletados.

Os dados foram analisados qualitativamente, considerando primeiro seus aspectos mais gerais e característicos de grupo em relação ao solicitado, sendo, então, relacionados à abordagem teórica que sustenta esta pesquisa, de modo a poderem ser discutidos.

\section{Os dados}

Um dos primeiros aspectos abordados nos questionários foi a percepção das relações interpessoais que cada um dos estudantes estabelece ou estabeleceu na universidade, durante o curso, com os colegas, professores, direção, servidores da secretaria e demais funcionários da instituição (Gráfico 01). Verificou-se que há uma predominância positiva em que a maioria percebe seus relacionamentos como bons ou muito bons. Apenas um dos participantes percebe suas relações como muito ruins.

\footnotetext{
${ }^{4}$ Em função da configuração dos gráficos às vezes aparecem 10 e 12 no eixo y dando a impressão de que o número de participantes oscila, mas são 11 os participantes da pesquisa.
} 


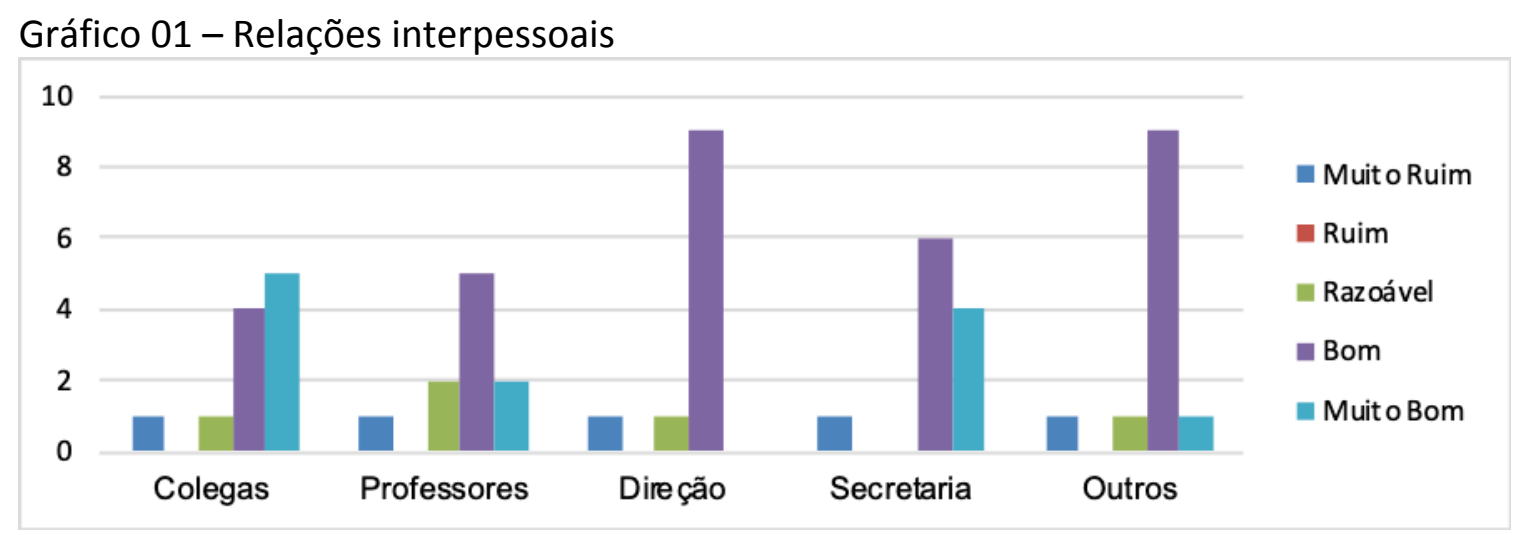

Fonte: os autores.

Em seguida, os participantes foram inqueridos a verificar a sua percepção referente a aspectos pessoais e posicionamentos que podem interferir nas relações e nos processos de aprendizagem (Gráfico 02). Eles deveriam analisar e manifestar suas percepções em relação a sentimento de estranhamento, de bem-estar e de aprendizagem de escrita.

Gráfico 02 - A universidade é o lugar onde

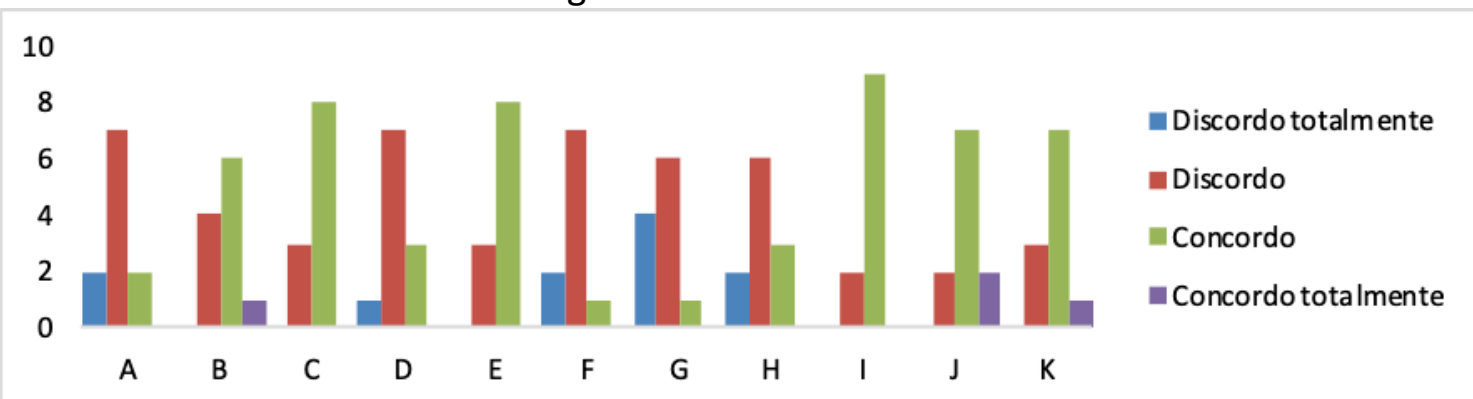

Fonte: Os autores. Legenda: A- Eu me sinto como um estranho; B- Eu faço amigos facilmente; CEu me sinto à vontade; D- Eu me sinto incomodado; E- Os outros estudantes parecem gostar de mim; F- Eu me sinto solitário; G- Vou porque sou obrigado; H- Eu me sinto entediado; I- Aprendo a me organizar nos estudos; J- Aprendo a raciocinar; K- Aprendo a escrever textos.

Visualiza-se nos dados que a maioria tem uma autopercepção positiva de si no tocante a sentir-se universitário, ou seja, no contexto de estudantes pertencentes a um grupo no espaço do campus, ainda que esse espaço universitário possa ter sido tomado como metonímia e não como o espaço físico em si. Ao observar o item A, por exemplo, vê-se que a maioria não se sente estranho, faz amigos facilmente (B) e se sente à vontade (C), sem perceber-se incomodado (D) ou entediado (H). Os participantes consideram também que o ambiente universitário colabora em sua formação, concordando que (I) aprendem a se organizar, $(J)$ a raciocinar e $(K)$ a escrever textos.

Os participantes também se manifestaram quanto à forma como percebem seus 
professores (Gráfico 03) sob alguns aspectos, tais como: se eles percebem os professores como incentivadores, como disponíveis para dirimir suas dúvidas, se disponibilizam espaço para manifestações de opiniões discentes, se utilizam de variação na forma de apresentar conteúdos com criatividade e se fazem avaliação adequada.

\section{Gráfico 03 - Como percebo meus professores}

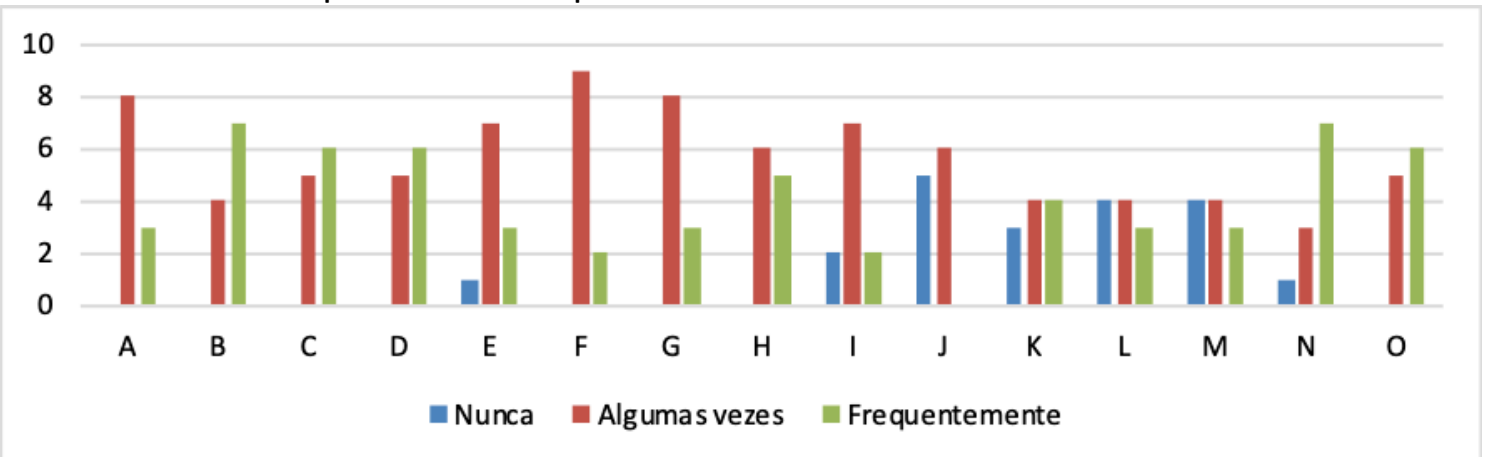

Fonte: Os autores. Legenda: A- Incentivam os estudantes a melhorar; B- Estão disponíveis para esclarecer as dúvidas dos estudantes; C- Dão oportunidade aos estudantes para exporem opiniões nas aulas; D- Relacionam-se bem com os estudantes; E- Continuam a explicar até que todos entendam o conteúdo; F- Mostram interesse pelo aprendizado de todos os estudantes ; G- Organizam bem a apresentação dos conteúdos; H- Realizam uma avaliação justa; I- Variam a maneira de apresentar/expor os conteúdos; J- Organizam passeios, projetos, jogos ou outras atividades; KCorrigem as atividades que recomendam; L- Utilizam diferentes estratégias para auxiliar estudantes com dificuldades; $\mathrm{M}$ - Procuram saber sobre os interesses dos estudantes; NDemonstram domínio da matéria que ensinam; O- Cobram as tarefas passadas para casa.

Em relação à percepção que os participantes têm de seus professores (Gráfico 03), nota-se que, segundo os estudantes, os professores nem sempre colaboram ou incentivam suas ações, ainda que frequentemente se coloquem à disposição. Outros aspectos que os participantes percebem de forma discrepante é que nem sempre os professores se interessam pelo aprendizado dos estudantes; entretanto, percebem que os professores cobram as tarefas com frequência, ainda que deixem a desejar quanto à organização e apresentação dos conteúdos. Para a maioria dos participantes, os professores incentivam os estudantes a melhorarem (A), o que se opõe à percepção de que os mesmos professores só mostram interesse pelo aprendizado dos estudantes algumas vezes (F). Esse resultado evidencia uma possível dificuldade de percepção e compreensão dos participantes quanto aos itens apresentados no mesmo tópico do questionário. Outro aspecto que pode indicar contrariedade na percepção e no entendimento é o posicionamento nos itens (N) e (G): domínio de conteúdo e organização e apresentação desses conteúdos. A maioria percebe que os professores têm conhecimento, mas têm dificuldade para organizar e apresentar esse 
conhecimento. Em relação ao item (H), avaliação justa, no sentido de adequada, os participantes ficaram divididos entre frequentemente e algumas vezes, o que pode indicar uma diferença de entendimento do termo "justa", pois nem sempre uma avaliação bem elaborada e criteriosa pode ser entendida como justa, a depender do que vale justiça para cada um dos atores/atrizes da interação. O mesmo posicionamento (frequentemente e algumas vezes) é percebido nos itens (C) e (D): dar oportunidade para os estudantes se expressarem e se relacionarem bem. Ao mesmo tempo que boa parte dos participantes indica que os professores limitam a participação e a exposição dos estudantes, os mesmos professores se relacionam bem com os estudantes, segundo a própria percepção dos estudantes.

Os participantes também manifestaram sua percepção sobre a frequência de leitura de alguns gêneros textuais em diferentes suportes ou plataformas, como indicado no Gráfico 04.

Gráfico 04 - Eu leio, frequência de leitura e gêneros

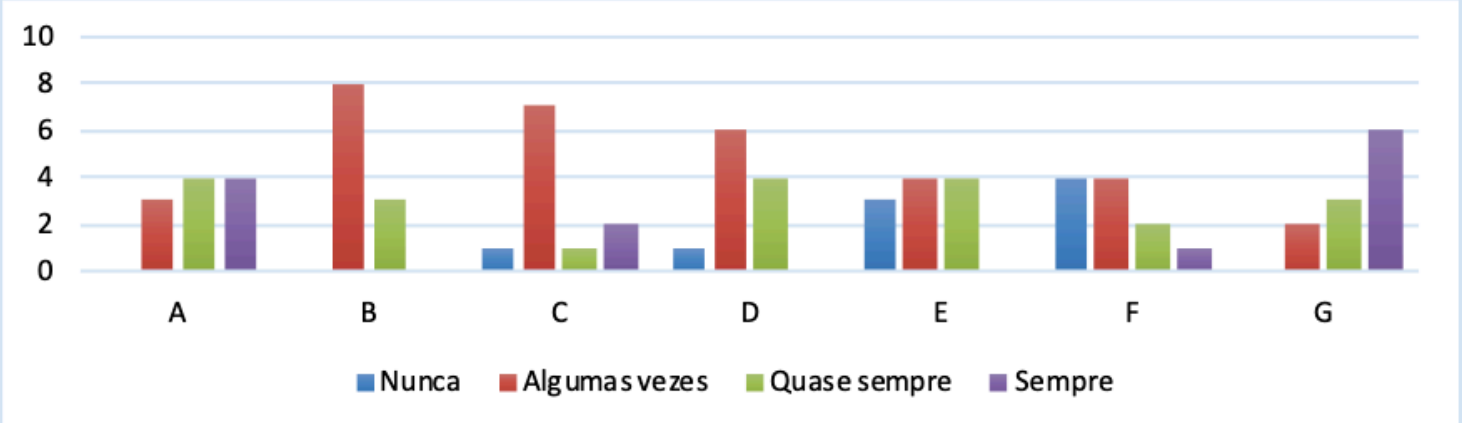

Fonte: Os autores. Legenda: A- romance, crônica e ficção em geral; B- história geral ou do Brasil; Clivros de poesia; D- jornais; E- revistas de informação geral; F- revistas em quadrinhos; G- sites de internet.

Ao observar os dados do Gráfico 04, percebe-se que a leitura de sites é a mais realizada entre os participantes e que jornais e livros de poesia (C) nunca são lidos por um dos sujeitos investigados. Romances, crônicas, ficção e revistas de informação em geral (A) também são bastante utilizados. Revistas em quadrinhos (F) nunca são lidas por boa parte dos participantes que responderam ao questionário.

Em relação à leitura (Gráfico 05), os sujeitos manifestaram sua percepção sobre o que leem, e o que se verifica é que a maioria não lê apenas por obrigação. Identifica-se também que, para a maioria, a leitura é uma atividade prazerosa e não se restringe ao necessário. Ainda, a ampla maioria entende que a Universidade é um local que incentiva a leitura. 
Gráfico 05 - Atividades de leitura

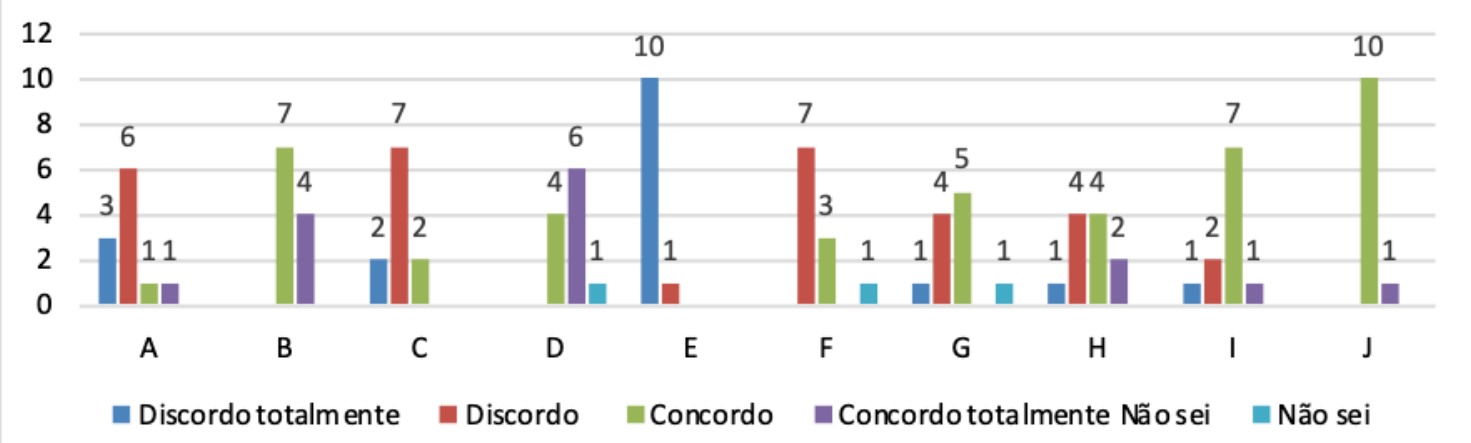

Fonte: Os autores. Legenda: A- só leio o que é necessário; B- ler é uma das minhas diversões preferidas; C- acho difícil ler livros até o fim; D- adoro ir a uma livraria; E- ler é uma perda de tempo; F- leio todos os livros indicados pelos professores; G- compro livros em lançamentos; $\mathrm{H}$ empresto/pego emprestado livros com os colegas; I- leio mais de um livro ao mesmo tempo; J- a Universidade me estimula a ler.

No Gráfico 05, observa-se que a maioria dos participantes não restringe a sua leitura apenas ao que é necessário para o curso (A) e que a leitura também faz parte da diversão deles (B). Os participantes também concordam que o ambiente de livrarias é um espaço que desperta interesse (D), compram livros em lançamentos (G) e admitem ler mais de um livro ao mesmo tempo (I). Mas, o mais relevante para o nosso estudo, é que todos consideram a universidade como um espaço que estimula a leitura (J).

A prática de ensino e a formação docente (Gráfico 06) é percebida pelos estudantes, professores em formação inicial, como algo positivo, mas com alguns aspectos dissonantes, como por exemplo, a concepção da prática docente (o estágio curricular) como algo não relacionado de forma significativa com os demais componentes curriculares do curso (outras disciplinas). Um aspecto positivo que ressaltamos é que os sujeitos da pesquisa percebem que ações de práticas de ensino não são apenas momentâneas ou pontuais durante o curso (restritas ao estágio).

Gráfico 06 - Práticas de Ensino e formação docente

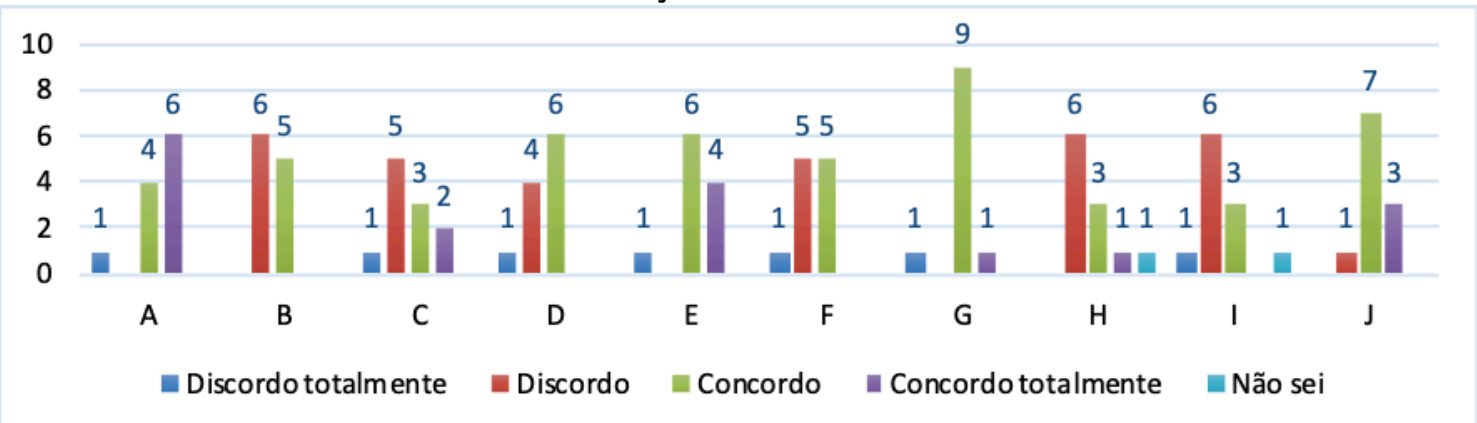

Fonte: Os autores. Legenda: A- Há razoável consenso entre professores e estudantes de que as 
atividades de práticas de ensino desempenham um papel fundamental na formação docente. B. As práticas de ensino são contempladas durante todo o curso. C. As práticas de ensino são contempladas apenas em momentos específicos (disciplinas de estágio) D. As práticas de ensino são vistas como momento de aplicação de teorias aprendidas no curso. E. As práticas de ensino constituem-se como experiências singulares de aprendizagem da docência. F. As práticas docentes (estágios) estão estreitamente relacionadas com os demais componentes curriculares do curso (outras disciplinas) G. A universidade e a escola buscam estabelecer uma relação de compreensão e ação cooperativa na formação inicial dos professores. H. A legislação das práticas de ensino (estágios) é trabalhada e discutida em sala de aula de modo que você enquanto professor em formação inicial se sente seguro para enfrentar a sala de aula. I. Da forma como o curso é organizado, ele informa e prepara você para a realização de práticas de ensino. J. As práticas de ensino são discutidas e planejadas em equipe em que estão presentes: você enquanto professor em formação inicial, o professor que atua na escola onde ocorre o estágio, o professor responsável pela orientação da prática, ou seja, há organização de forma integrada e dialogada.

Ao observar os resultados do Gráfico 06, verifica-se que apenas um participante discorda que as práticas de ensino desempenham um papel fundamental na formação docente (A). Todos os participantes concordam que as práticas de ensino (E) são experiências singulares da docência. Entretanto, o grupo de participantes discorda quanto às práticas de ensino (B). A maioria discorda que as práticas de ensino são contempladas durante todo o curso. A maioria discorda também que os documentos que legislam as práticas de ensino $(H)$ são discutidos em sala de aula, ou seja, há uma carência na orientação e, por isso, sentem-se inseguros para enfrentar a sala de aula. A maioria também percebe de forma negativa a organização do curso (I). Um aspecto positivo e relevante, segundo a percepção dos participantes, é que as atividades de práticas de ensino são discutidas e planejadas em equipe (J). Todos também concordam que a universidade e a escola buscam estabelecer uma relação de cooperação $(G)$ na execução das atividades de formação inicial de professores. O grupo está igualmente dividido em relação às práticas docentes e às relações estabelecidas com os demais componentes curriculares (F). Há divergência em que uma parte dos participantes percebe que há relação bem estabelecida entre o estágio e as outras disciplinas do curso e outra parte dos participantes indica que não percebe uma estreita relação entre estágio e outras disciplinas do curso.

Além de práticas de ensino em geral, foi referenciada nos questionários a prática específica de ensino de leitura. Os resultados, que podem ser visualizados no Gráfico 07, mostram uma boa percepção do processo formativo de práticas de ensino de leitura durante o curso. 
Gráfico 07 - Práticas de Ensino de Leitura

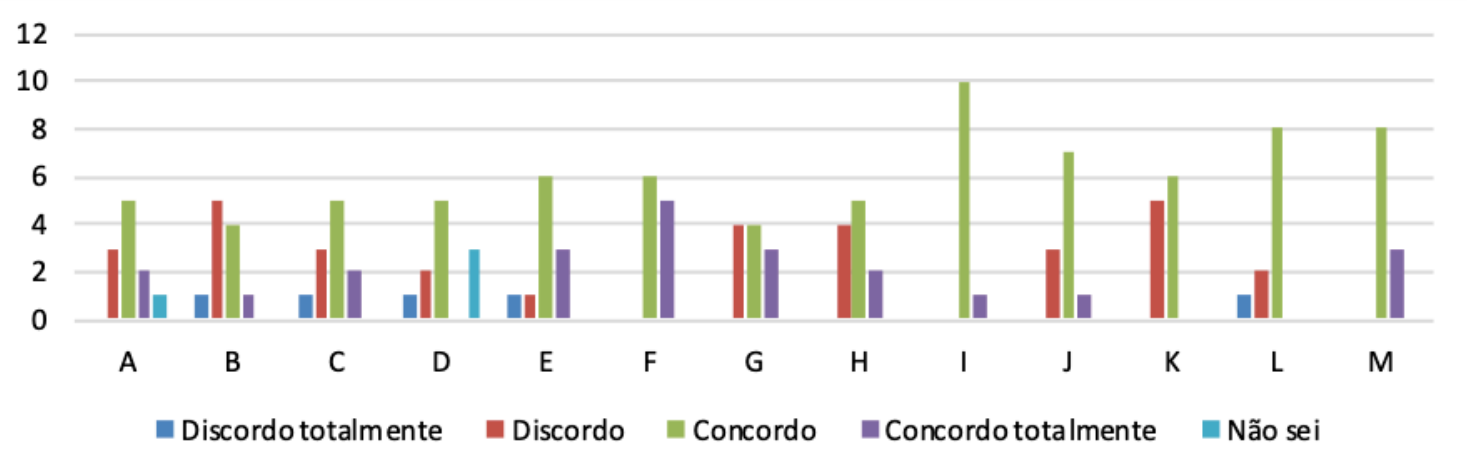

Fonte: Os autores. Legenda: A- Há razoável consenso entre professores e estudantes de que as atividades de leitura são entendidas como objeto de conhecimento em si mesmas e como instrumento necessário para a realização de novas aprendizagens. B- Existem disciplinas que tratam explicitamente do ensino de leitura e de estratégias de leitura no curso. C- As práticas de ensino de leitura e as estratégias adotadas devem relacionar-se com o objetivo estabelecido, ou seja, com a finalidade por que lemos. D- Em relação ao processo de leitura, os pesquisadores e os professores do curso apresentaram aspectos em que concordam em considerar que as diferentes explicações podem ser agrupadas em torno dos modelos hierárquicos ascendentes e descendentes. E- As habilidades de decodificação são de grande importância para a que o leitor compreenda o texto. F- O conhecimento prévio, isto é, o conhecimento de mundo e os recursos cognitivos também são aspectos relevantes a serem considerados no processo de leitura. G- Nas práticas de ensino de leitura realizadas no decorrer do curso, foi discutida a importância do ponto de vista do autor, do professor, do estudante e a consonância com os objetivos dos textos lidos para as diferentes disciplinas do curso. $\mathrm{H}$ - Nas práticas de ensino de leitura realizadas no decorrer do curso, foi discutida a relevância da compreensão e da aprendizagem, ou seja, o leitor proativo que processa e atribui significado àquilo que está escrito em uma página. I- Nas práticas de ensino de leitura realizadas no decorrer do curso, foram discutidas as questões da alfabetização, do domínio do código, da consciência metalinguística e do letramento. J- Nas práticas de ensino de leitura realizadas no decorrer do curso, foram discutidas e apresentadas estratégias de compreensão leitora. K- Nas práticas de ensino de leitura realizadas no decorrer do curso, foram discutidas questões de planejamento para a leitura, ou seja, ações que levam à compreensão e que são realizadas antes da leitura, durante a leitura e depois da leitura. L- A partir das práticas de ensino de leitura realizadas no decorrer do curso, com o intuito de prepará-lo para a prática docente, você está apto para atuar como alfabetizador ou para preparar seus estudantes para desenvolverem habilidades de leitura e compreensão leitora. $M$ - A partir das práticas de ensino de leitura realizadas no decorrer do curso, você está ciente de que existem diferentes perspectivas teóricas para abordar e discutir o ato de ler e os resultados alcançados a partir da leitura.

Ao observar os resultados no Gráfico 07, percebe-se que a maioria concorda que as atividades de leitura são entendidas como objeto de conhecimento em si mesmas e como instrumento necessário para a realização de novas aprendizagens (A). Em relação a disciplinas que tratam explicitamente do ensino de leitura (B), os resultados mostram um descompasso entre os participantes, pois a metade do grupo concorda que há, e outra metade discorda. Entretanto, todos frequentam o mesmo curso de graduação, o que indica que há diferentes percepções para 
os mesmos objetos ou instrumentos oferecidos. Em relação às práticas de leitura e seus objetivos (C), a maioria concorda que sempre devemos ler a partir de um objetivo pré-estabelecido. Sobre os modelos de leitura (D), a ampla maioria concorda que são trabalhados os modelos hierárquicos ascendentes e descendentes de leitura. A maioria dos participantes também concorda que as habilidades de decodificação (E) são de grande importância para que o leitor compreenda o texto. Outro aspecto com o qual todos os participantes concordam é sobre o conhecimento prévio (F). Segundo os dados, o conhecimento de mundo e os recursos cognitivos são aspectos relevantes a serem considerados no processo de leitura. Em relação ao ponto de vista (G), há certa divergência nas respostas, em que uma parte discorda que são trabalhados, mas a maioria concorda ou concorda totalmente que os aspectos apontados são discutidos nas disciplinas do curso, do ponto de vista do autor, do professor, do estudante, em consonância com os objetivos dos textos lidos para as diferentes disciplinas do curso. Outro aspecto em que os participantes apresentaram percepções e entendimentos divergentes foi em relação ao posicionamento leitor $(H)$ nas práticas de ensino de leitura realizadas no decorrer do curso. Foi discutida a relevância da compreensão e da aprendizagem, ou seja, o leitor proativo que processa e atribui significado àquilo que está escrito em uma página. Parte do grupo discorda que isso é tratado de forma adequada, mas a maioria concorda com a forma como é feito.

Um elemento positivo para o nosso estudo é relativo às práticas de ensino: (I) - Nas práticas de ensino de leitura realizadas no decorrer do curso, foram discutidas as questões da alfabetização, do domínio do código, da consciência metalinguística e do letramento. Todos os participantes da pesquisa concordam que isso é tratado no curso convergindo com o aspecto apontado no item (M): A partir das práticas de ensino de leitura realizadas no decorrer do curso você está ciente de que existem diferentes perspectivas teóricas para abordar e discutir o ato de ler. Quanto aos resultados alcançados a partir da leitura, todos estão cientes que há diferentes perspectivas teóricas que podem tratar da leitura. Consideramos relevante que os professores, especialmente mas não exclusivamente de língua, tenham clareza de suas responsabilidades, mas que, além das responsabilidades, tenham clareza teórica, pois é esta que dá sustentação para as suas ações pedagógicas e linguísticas no ensino e aprendizagem de leitura.

\section{Reflexões, apontamentos e discussão sobre os dados}

A forma como os seres humanos se percebem e se avaliam constitui-se numa poderosa ferramenta e, de certa forma, trata-se de uma necessidade humana, que contribui de maneira 
essencial para o seu desenvolvimento. Uma percepção positiva de si e uma percepção positiva da realidade indicam um grau de responsabilidade sobre si e sobre as suas reações e relações interpessoais. Simões e colaboradores (2008) consideram o autoconceito ou autopercepção relevante em diversos contextos, particularmente no educativo, pois seu caráter multidimensional Ihe confere uma posição privilegiada pelo seu impacto na dimensão comportamental mais geral quanto aos resultados escolares e ainda quanto à motivação para executar e levar a cabo as tarefas. Ao observarmos os dados do Gráfico 01, percebemos que esse aspecto parece relevante, pois, para a maioria dos participantes, a autopercepção é positiva, bem como positiva é a percepção das relações interpessoais e positivas são, em sua maioria, as relações estabelecidas ou a percepção das relações de ensino aprendizagem de leitura.

Os estudos de Tonelotto e Gonçalves (2002) mostram que crianças que se percebem de forma negativa, ou seja, que apresentam uma autopercepção depreciativa em relação a atividades escolares efetivamente apresentam um rendimento inferior quando comparadas a crianças que apresentam uma autopercepção positiva (que se reconhecem como bons estudantes). O que se percebeu em nosso levantamento de dados é que apenas um dos sujeitos tem uma percepção negativa de suas relações interpessoais e as avalia como ruins. O mesmo participante teve um posicionamento mais pessimista, mostrando maior insatisfação em relação aos demais aspectos avaliados no questionário e deu mais respostas negativas para o processo de formação. Para analisar se tal efeito percebido nas crianças se repete e se confirma em adultos, seria necessário um estudo que levasse em conta não apenas aspectos perceptuais, mas também comportamentais e de desempenho dos estudantes.

O que parece evidente e consensual é que, ao longo de sua história, o ser humano usa instrumentos como elementos mediadores para aprender e, consequentemente, desenvolver as funções psíquicas típicas de sua espécie, as quais estão relacionadas aos mecanismos intencionais e às ações conscientemente controladas, tais como planejamento, memória, atenção voluntária, imaginação, linguagem. Essas funções não são processos inatos, diferenciam-se de mecanismos mais rudimentares (ações puramente reflexas e automatizadas) e se desenvolvem ao longo da internalização de formas culturais de comportamento, ou seja, são construídas na história social do homem, em sua relação com o mundo. Essas relações não acontecem de forma direta, mas mediadas por ferramentas exclusivas da atividade humana. Segundo Vigotski (1998), a característica central das funções elementares é que elas são total e diretamente determinadas pela estimulação procedente do meio ambiente. Para as funções superiores, a característica 
central é a estimulação autogerada, isto é, a criação e o uso de estímulos artificiais que se transformam em causas imediatas do comportamento. Nesse contexto, incluem-se, por exemplo, os processos de formação e profissionalização e a percepção dos sujeitos em relação ao formador (Gráfico 03), no caso, a percepção que os estudantes têm dos professores formadores. Nos dados registrados, há tendência para uma avaliação positiva, ainda que reconheçam que nem sempre, durante o curso, as ações tenham sido suficientemente boas.

Para que se humanize, o homem tem a necessidade fundamental de apropriar-se de um conjunto de processos, signos e instrumentos, que lhe permitem a construção do seu ser social e histórico. A relação do indivíduo com o meio cultural onde está inserido possibilita-lhe apropriarse de conhecimentos que favorecerão seu desenvolvimento. Assim, "o indivíduo, a criança, não é apenas 'colocado' diante do mundo dos objetos humanos. Para viver deve agir (ativamente e) adequadamente neste mundo" (LEONTIEV, 1978, p. 254). A ação se dá de forma significativa pela linguagem.

A linguagem é uma capacidade específica da espécie humana, utilizada para comunicar, fundamentalmente na sua vertente oral mas também sob a modalidade escrita, utilizando um sistema de signos arbitrários (LOPES, 2008). Cruz (2007, apud RODRIGUES 2012) acrescenta ainda que a linguagem se manifesta numa hierarquia de sistemas verbais e não verbais, seguindo uma determinada sequência, nomeadamente a linguagem interior, a linguagem auditiva ou falada e a linguagem visual ou escrita.

Com base nos pressupostos da Teoria Histórico-Cultural, a linguagem desempenha papel fundamental no desenvolvimento das funções psicológicas superiores, pois, por exemplo, enquanto uma faca é um instrumento que potencializa a ação do homem sobre a natureza, a linguagem é um instrumento que atua no controle das ações psicológicas do sujeito como um elemento mediador interno. Assim, Vigotsky (1993) afirma que o homem, ao internalizar a linguagem, torna-se capaz de imaginar, estabelecer relações, pensar e falar sobre um objeto sem que ele esteja presente. Nesse sentido, o sujeito, por meio dos signos que representam objetos, seres vivos etc, se liberta da realidade concreta, e a sua relação com o mundo passa a ser mediada. Foi pensando nessa mediação que se considerou a percepção dos estudantes sobre o ensino e a aprendizagem de leitura.

\subsection{Leitura, mediação, processos perceptivos e cognição}


No entendimento de que a leitura é um processo mediador que contribui para o desenvolvimento social e psicológico do ser humano, considera-se que ela se constitui como instrumento da linguagem humana, compreendida aqui mais do que como a decodificação de um código escrito, como um produto cultural e instrumento de transformação, sendo um meio que amplifica e aumenta as possibilidades de reflexão sobre a própria língua (SOUZA; WEIRICH; PROCAILO, 2017) e que promove o acesso ao conhecimento. Ao direcionar o olhar para o Gráfico 07, percebe-se que os participantes entendem a leitura como objeto de conhecimento em si mesma e como instrumento necessário para a realização de novas aprendizagens, em que ações ativas dos leitores demandam tanto de funções puramente perceptivas (necessárias para o aspecto inicial da leitura, visualização e decodificação) quanto de ações cognitivas para a compreensão do lido.

As funções perceptivo-cognitivas estão envolvidas em todas as etapas do processo de aprendizagem e, por isso, desempenham um papel fundamental. Nas fases iniciais ou elementares, é a percepção sensorial a mais utilizada, distinguindo estímulos visuais de auditivos e supervisionando a correta execução de registros gráficos e palavras. Em fases posteriores, nas quais outros elementos linguísticos e metalinguísticos, como, por exemplo, a morfologia, adquirem importância, são as funções cognitivas que lideram o processo (REBELO, 1991). Nesse sentido, parece que os elementos perceptivos, tanto da percepção da realidade (contexto) quanto da autopercepção situada (Gráficos 01 e 02) podem ser relevantes para as funções perceptivocognitivas elementares, mas não devem interferir nas fases posteriores em que as questões cognitivas são predominantes. O mesmo deve ocorrer em relação aos dados do Gráfico 03, em que a forma como os estudantes percebem os professores, na prática, não deveria ser fator relevante para o desenvolvimento cognitivo de aprendizagem de leitura ou interferir de forma relevante em seu processo de formação, uma vez que a busca do conhecimento (em se tratando de adultos) é mais de sua responsabilidade e menos do outro.

De acordo com Viana e Teixeira (2002), desenvolvimento cognitivo e idade, consciência linguística e metalinguística, conhecimento lexical e sintático, conhecimento implícito e explícito das funções e do funcionamento da língua, capacidade de emitir julgamentos sobre a sintaxe e a morfologia, consciência fonológica, memória de trabalho para material verbal, relações entre a consciência fonológica e a memória de trabalho para material verbal são condições essenciais à aprendizagem da leitura, acrescentando a consciência fonológica e a sua relação com a memória de trabalho como mais um aspecto fundamental ao desenvolvimento da leitura. Em relação a esse 
aspecto, o desenvolvimento dessas habilidades pode ser impactado pela frequência de leitura e pela variação de gêneros lidos. De acordo com os dados do Gráfico 04, percebe-se que o arcabouço de leitura participantes é bastante variável quanto aos gêneros e frequente quanto à realização de leituras.

Além da idade e do desenvolvimento cognitivo, quando pensamos o processo de aprendizagem da leitura, também o vinculamos ao processo de escolarização. Associada ao processo de escolarização podemos estabelecer uma relação, tal como: Pré-Escolar - período para a maturação à leitura, pois promove aproximação, criação de vínculos e desenvolvimento de preditores para a leitura. Ensino Básico 1ํciclo (1으 ao 5ㅇano) - período ou estágio inicial de aprendizagem de leitura. 2ำ ciclo (6 ao 9o ano) - estágio de desenvolvimento do leitor e de suas habilidades em leitura. Ensino Básico - 3ํciclo ou Ensino Médio - estágio de desenvolvimento da eficiência leitora (LOPES, 2008). Acrescentamos que o ensino superior deveria ser o estágio para aperfeiçoamento da eficiência, ou seja, um constante aprimoramento. Se observarmos o Gráfico 05, a maioria dos participantes percebe a ação ou ato de ler como um ato de prazer, como uma diversão e não lê apenas o necessário, ou seja, vai além da obrigatoriedade do curso. Entretanto, a maioria não lê todos os livros indicados pelos professores, mas lê mais de um livro ao mesmo tempo, indicando, assim, uma constante atualização e aperfeiçoamento.

Existem diversos autores, tais como de Koch (2011), Kleiman (2002), Lopes (2008), Heinemann e Viehweger (1991 apud RODRIGUES, 2012), que evidenciam que a maior ou menor facilidade para aprender a ler relaciona-se com a capacidade de desempenho em tarefas cognitivas de caráter lógico e analítico de processamento. Kleiman (2002, p. 50) chama de processamento os "procedimentos para os quais utilizamos conhecimento sobre o qual não temos reflexão nem controle consciente e é realizado estrategicamente e não através de regras".

Segundo Dell'Isola (2001), a Psicolinguística estabelece alguns critérios relevantes a serem observados na construção de tarefas para avaliação do processamento discursivo. Esses critérios podem ter um caráter mais linguístico, ligando-se à estrutura de superfície do texto, ou mais pragmático-discursivo, ligando-se a aspectos que demandam o processamento de informação nem sempre explicitamente dada. São exemplos de critérios considerados: a extensão do texto; o número de palavras e de proposições; a complexidade das estruturas oracionais; as estruturas sintática e semântica de um texto, que influenciam a demanda de recursos recrutados para o seu processamento (FRIEDERICl; WEISSENBORN, 2007); os aspectos estruturais relacionados à coesão e à coerência textual, sendo que textos que apresentam sinalizadores da coesão textual, como as 
conjunções, e uma referenciação clara facilitam a compreensão leitora (DASCAL, 2006), e textos cujas ideias estejam bem articuladas também facilitam o entendimento. Dessa forma, o leitor/ouvinte consegue criar no cérebro redes de significação que se acoplam ao seu conhecimento prévio de forma significativa, às suas representações mentais. O domínio da temática do texto também pode ser um facilitador. Em relação aos fatores pragmático-discursivos, destacam-se o grau de informações implícitas, a exigência de conhecimento prévio devido à temática do texto (KOCH, 2011; KLEIMAN, 2002). Esses elementos podem ser ilustrados, por exemplo, com os dados dos Gráficos 06 e 07, em que a percepção do processo de ensino aprendizagem de leitura e a formação docente mostra que há relações coerentes, porém, não únicas. Para realizar a avaliação dos elementos apresentados, os estudantes precisam estar cientes de seus conhecimentos adquiridos no percurso da formação na graduação e de conhecimentos anteriores e de suas capacidades de controle de conhecimentos e procedimentos.

Segundo Rodrigues (2012), os vários autores se mostram unânimes na compreensão de que a tarefa da leitura se constitui como uma atividade múltipla e complexa, implicando um conjunto de processos de diferentes tipos. A maior parte destes processos, no caso de um leitor fluente, é automática e não-consciente. Dessa forma e reforçando a ideia de que a leitura é uma atividade cognitiva complexa, que abrange um amplo leque de processos psicológicos e cognitivos de diferentes níveis, é sugerido que ela se inicia com um estímulo visual e termina com a compreensão de um texto. Para chegar de uma à outra, é necessária ação global e coordenada de diferentes processos que ultrapassam a escolarização (RODRIGUES, 2012).

Para além da escolaridade, parece existir consenso entre os pesquisadores de que existem pelo menos dois processos importantes implicados na atividade de leitura e na função dessa atividade: os processos de nível inferior, implicados na decodificação, e os processos de nível superior, implicados na compreensão (DAS; NAGLIERI; KIRBY; KIRBY, 1994; LOPES, 2008). Outros estudos, também apresentados por Rodrigues (2012, p. 28), "sugerem que a decodificação e a compreensão são dois processos igualmente importantes para se alcançar o domínio da leitura mas que não são simétricos". Ou seja, ao par da leitura propriamente dita, no que se refere aos seus processos específicos, como decodificação e identificação de palavras, existe uma função da leitura que diz respeito à compreensão. Cruz (2004 apud RODRIGUES 2012, p. 28) refere ainda que, apesar do carácter interativo entre os dois níveis, existe uma limitação: "a compreensão não pode ser realizada sem a mediação da descodificação, enquanto que o contrário já é possível”. Isto é, se não existir decodificação das palavras, não haverá lugar para os processos de compreensão. 
A compreensão de um texto exige que os processos de decodificação, identificação e reconhecimento das palavras escritas estejam automatizados.

\subsection{Como todos esses conceitos podem se apresentar e interferir na formação inicial de professores?}

Falar sobre a formação de professores no Brasil é fazer uma reflexão do seu papel no contexto atual da escola. Nas últimas décadas, o tema da formação de professores se tornou central no cenário acadêmico brasileiro e na mídia em geral. O cenário atual aponta para a necessidade de, além de pensar a formação de forma crítica e reflexiva, organizá-la a partir de uma formação inicial que apresente um olhar mais cuidadoso e analítico para a recomposição do espaço acadêmico, articulando-o ao debate sociopolítico da educação.

Reconhecidamente a leitura é fonte de construção do saber, por isso, fundamental na educação em qualquer nível. Tendo em vista sua importância no processo de compreensão de mundo, a leitura constitui uma demanda social e uma ferramenta indispensável para o delineamento de novas fronteiras do saber. Sendo professor responsável pelo ensino da leitura na escola, ele é, consequentemente, responsabilizado também pelos seus resultados negativos e positivos, ou seja, pelo desempenho leitor de seus estudantes. Para isso, é fundamental que estejam claros os aspectos teóricos que sustentam o processo de ensino de leitura, como por exemplo, os tópicos $G, H, I, J, K, L$ do Gráfico 07 , segundo os quais, respectivamente, na formação de professores para o ensino de leitura, considera-se que: há o envolvimento de diferentes pontos de vista no processo de produção de sentidos a partir do escrito (G); é o leitor quem orquestra a leitura e quem se envolve nos processos de compreensão e aprendizagem $(H)$; o conhecimento acerca do funcionamento do sistema de escrita, suas regras, usos e funções (desde o processo de alfabetização) é necessário (I), assim como é fundamental o conhecimento acerca do comportamento estratégico do leitor, que deve ser ensinado, com vistas ao alcance da compreensão (J); leitura requer planejamento, sistematização, execução, elaboração e revisão, não necessariamente de forma linear e sequencial $(K)$; e cabe à formação inicial oferecer condições teórico-metodológicas para o trabalho docente de ensino da leitura objetivando a compreensão (L).

Ao dar destaque à importância do professor para a formação de leitores proficientes, não se quer atribuir somente a ele a responsabilidade de garantir aos estudantes o desenvolvimento das capacidades de leitura. Sabe-se que esse é um problema relacionado com as desigualdades 
sociais, com as oportunidades de acesso aos livros e à cultura letrada, como um todo. Consequentemente, para a maioria dos estudantes das escolas públicas, os primeiros contatos com um acervo de livros e textos de qualidades minimamente reconhecidas acontece ao entrar na escola de ensino fundamental. Esse fato torna ainda mais significativo o papel de mediação, que é conferido aos professores desse nível de ensino.

De acordo com os estudos psicolinguísticos, defende-se que é função da escrita, de algum modo, representar a linguagem oral e, em particular, é função das escritas fonológicas codificar a fala. A função inversa da fala, de acordo com Morais e Kolinsky (2015), é realizada pela leitura. A habilidade específica dos humanos para decodificar palavras, isto é, para ler é a que permite processar as palavras escritas de uma língua, de tal modo que o leitor constrói conhecimentos implícitos ou explícitos sobre o código ortográfico de sua língua. Isso implica para o professor ter clareza sobre os aspectos teóricos envolvidos (Ver, por exemplo, os tópicos do Gráfico 07, que se referem a aspectos teóricos, alguns dos quais foram mencionados acima). Tais conhecimentos demandam elementos cognitivos para a leitura.

Sobre a leitura como processo cognitivo, concordamos com Dehaene (2012), para quem se trata de processo que se inicia na retina, portanto, uma atividade perceptiva, de onde se projetam os fótons reenviados pela página. Se os detalhes faltam, seja após uma lesão retiniana, após uma lesão das áreas cerebrais visuais, ou após um artifício experimental que mascare seletivamente a região da fóvea, a leitura se torna inviável, não sendo possível reconhecer as palavras. Reconhecer uma palavra consiste, primeiramente, em analisar a cadeia das letras, descobrir as combinações entre elas (sílabas, prefixos, sufixos, radicais das palavras), para, enfim, associá-las aos sons e aos sentidos. É somente porque as operações foram automatizadas por anos de aprendizagem e porque se desenvolvem em paralelo, fora de nossa consciência, que persistiu durante tantos anos a hipótese naîve de uma leitura imediata e global.

Em relação à interatividade e à historicidade, comunga-se com as perspectivas de Orlandi (1988), Kleiman (1989), Souza e Garcia (2012) e Souza, Seimetz-Rodrigues e Weirich (2019), que se aproximam ao tratar a leitura como um processo complexo e dinâmico, em que o leitor realiza um trabalho ativo de produção de sentidos de um texto, em um contexto social e cultural, a partir dos propósitos que estabelece e de seus conhecimentos prévios, acionados em uma dada situação, isto é, os conhecimentos de mundo, temático, linguístico, textual e o conhecimento relativo a como realizar a tarefa. Há que se considerar, ainda, que todo esse processo, quando se está falando de aprendizagem relativa ao uso da tecnologia da escrita, acontece mediado. No caso, o 
professor, mesmo em formação inicial, mas que atua na escola, faz a mediação da aprendizagem da leitura de seus estudantes.

Rudell e Unrau (1994), em um texto seminal, defendem e explicitam o papel do professor na aprendizagem a leitura, entendida como um processo de construção de sentidos em que estão envolvidos o leitor, o texto e o professor em determinada situação e contexto. Heinig (2019, p.108), inspirada nas ideias desses autores, esclarece que, quando se trata de ensinar a ler,

\begin{abstract}
é preciso destacar o ambiente de aprendizagem, pois é nele que ocorre o processo de negociação de sentidos, isto é, os sentidos são criados como resultado da interação entre leitor, texto, professor e a sala de aula. Além disso, o ambiente de aprendizagem tem forte influência sobre a motivação dos alunos para se engajarem na leitura a fim de agirem sobre o texto para que ocorra a sua compreensão, o que pode ocorrer apenas pela ação do leitor ou com a mediação de um leitor experiente. Nessa perspectiva, destaca-se o papel do professor como o que seleciona ou indica os textos para leitura, bem como é responsável pelas tarefas que antecedem ou precedem a leitura do texto; ele assume o papel crítico na orquestração e negociação dos sentidos do texto no contexto da sala de aula, sendo este espaço o da interação. Ainda neste ambiente de aprendizagem, é preciso considerar outros aspectos: a tarefa, a origem da autoridade e os significados socioculturais, ou seja, é preciso ler mais que o texto.
\end{abstract}

Ao professor parece ser cara a ciência de que existem e são possíveis de serem identificados pelo menos dois momentos importantes e distintos no processo de leitura, sendo: 1은 Leitura emergente em que a alfabetização funciona como chave à produção de sentidos a partir do escrito, onde a escrita se apresenta como uma propriedade tecnológica cultural e que leitura se aprende e não se adquire por imersão em contexto em que o outro se utiliza dela; 2ㅇ Leitura proficiente, que implica processos e procedimentos. Estando automatizados o conhecimento e os processos relativos às operações básicas entre as quais está a decodificação, podem-se alocar atenção e recursos à produção de sentidos textuais para além da significação básica e também para além do texto (SOUZA; GARCIA, 2012).

Para se constituir em um lugar privilegiado de acesso à leitura de livros e de textos em sua diversidade, direito muitas vezes negado aos estudantes (LAJOLO; ZILBERMAN, 1996; MORAIS, 2014), à escola cabe assumir seu papel como espaço oficialmente responsável pelo processo intencional de formar leitores. Conforme indicado no Gráfico 02, os estudantes percebem o espaço universitário como local que promove a reflexão e o incentivo à leitura e reconhecem também que, além de eventos efetivos de leitura, são importantes os conhecimentos teóricos a ele relacionados, tal como evidenciam os dados constantes do Gráfico 07.

Ao tratar da leitura do professor, Freire $(1996$, p.13) alerta que "[...] precisamos ler com seriedade, mas, acima de tudo, precisamos aprender o que é ler realmente!", no sentido de 
compreender a conexão entre o texto e o contexto, bem como articular o texto/contexto com o nosso contexto, o contexto do leitor. É necessário garantir ao professor o direito de aprender a ler para além da capacidade óbvia de decodificar, acionando o conhecimento de mundo para relacioná-lo com os temas do texto, com outros textos, e assim prever, hipotetizar, inferir, comparar informações, generalizar, situando o texto em seu contexto (ROJO, 2009). Portanto, se o professor não tiver acesso a esta forma de leitura, provavelmente ficará à margem da informação e de um tipo de conhecimento da sociedade - aquele que é relativo à escolarização e que não se veicula senão pela escrita -, refletindo-se no processo educativo.

\section{Construção de referências}

Quando iniciamos os estudos sobre percepção e processos perceptivos, também nos fizemos alguns questionamentos sobre como o estudante/professor em formação inicial se percebe e percebe seu contexto formativo e como os estudantes do curso de Licenciatura de Letras Português são instruídos e formados quanto aos aspectos de aprendizagem de leitura e, além disso, de que maneira estudantes do curso de Licenciatura de Letras Português aprendem para poder ensinar.

Para algumas dessas questões se encontraram respostas; para outras, ao invés de respostas, surgiram novos questionamentos. Percebeu-se, por exemplo, que a maioria dos autores de diversos programas de ensino da leitura aceita como fazendo parte da definição de leitura os seguintes elementos: percepção (reconhecimento de palavras), compreensão e interpretação, apreciação e aplicação. Tais elementos podem ser identificados nos resultados dos dados, em que a interpretação e a compreensão aparecem sob diferentes perspectivas em que nem todos os participantes os percebem da mesma forma. Tal observação pode ser constatada nos resultados dos Gráficos 05, 06 e 07, em que algumas respostas parecem contraditórias, como por exemplo, a percepção referente às ações dos professores formadores e o ensino explícito de leitura nos componentes curriculares.

Como o sistema de escrita da língua portuguesa é alfabético, as unidades da fala que são codificadas na escrita são os fonemas. Estes se constituem como as unidades da segunda articulação, que introduzem diferenças nos significados das palavras. Identificou-se, nos estudos da área da linguagem e cognição, que devido a tais características, o desenvolvimento dos sistemas perceptivos, especialmente auditivo e visual, são de grande relevância. Entretanto, para 
além de um ato perceptivo, a leitura é primordialmente um ato cognitivo e, como indicado nos dados do Gráfico 07, os estudantes consideram muito importante a habilidade de percepção e do processo de decodificação com vistas à compreensão do texto lido.

De acordo com Rodrigues (2012), nosso sistema de escrita não é alfabético puro ou homogêneo, isto é, não há um fonema único para cada registro grafêmico e, como tal, a correspondência fonema-grafema não é linear. Os grafemas "e" e "o", por exemplo, podem representar dois fonemas e, naturalmente, um número variado maior de realizações fonéticas. Em relação a esse aspecto, Martins e Niza (1998) reforçam que é fundamental os leitores compreenderem as regras inerentes à ligação entre as unidades de fala e as unidades de escrita. Ao observarmos os dados do Gráfico 07, constatamos que os sujeitos participantes do estudo concordam que esses e outros conhecimentos linguísticos relacionados ao processo de aprendizagem referentes à leitura são importantes e necessários para a atuação pedagógica e para o êxito na atividade de ler.

Identificou-se também que as funções perceptivo-cognitivas desempenham um papel fundamental, pois estão envolvidas em todas as etapas do processo de aprendizagem. Conforme já dito, nas fases elementares, é a percepção sensorial a mais utilizada, distinguindo estímulos visuais de auditivos e supervisionando a correta execução de grafismos e palavras. Em fases posteriores, nas quais a morfologia adquire importância, até as fases hierarquicamente superiores, são as funções cognitivas que lideram o processo (REBELO, 1991). Para que esse processo ocorra, é necessário um processo de ensino adequado, como podemos perceber no Gráfico 06. Para os estudantes participantes desta pesquisa, as práticas de ensino são vistas como momento de aplicação de teorias aprendidas no curso, e as práticas de ensino se constituem como experiências singulares de aprendizagem da docência como concretude do desenvolvimento perceptivo e cognitivo.

Em síntese, em relação aos dados coletados e aos posicionamentos teóricos identificados, constatou-se que, quanto mais positiva a percepção e a autopercepção da realidade e do processo de ensino/aprendizagem, melhor é o resultado, posicionamento já apresentado anteriormente no texto. Os dados seguem a direção de outras pesquisas da área. Verifica-se uma tendência positiva na percepção da realidade e da autopercepção nas interações interpessoais, bem como uma percepção positiva frente à formação no curso de Letras e à atuação dos professores formadores. Entretanto, dados os limites da pesquisa, não pudemos estabelecer relações e generalizações sobre os efeitos dessa percepção nos processos de leitura dos envolvidos. Destacamos, mesmo 
assim, que os estudos bibliográficos propõem que o impacto maior se dá em crianças em processos de escolarização e menos em adultos, público-alvo do nosso estudo.

\section{Referências $^{5}$}

CHAUI, Marilena. Convite à filosofia. São Paulo: Ática, 1999.

DAS, Jagannath Prasad, NAGLIERI, Jack A. KIRBY, John R. Assessment of Cognitive Processes: the P.A.S.S. Theory of Intelligence. Toronto: Allyn and Bacon, 1994.

DASCAL, Marcelo. Interpretação e compreensão. São Leopoldo: Unisinos, 2006.

DEHAENE, Stanislas. Os neurônios da leitura. Tradução de Leonor Scliar-Cabral. Porto Alegre: Penso, 2012.

DELL'ISOLA, Regina Lúcia Péret. Leitura: inferências e contexto sociocultural. Série Educador em Formação. 2. ed. Belo Horizonte, MG: Formato, 2001.

DESCARTES, René. Meditações sobre a filosofia primeira (MED). Coimbra: Livraria Almedina, 1988.

DORON, Roland; PAROT, Françoise. Dicionário de Psicologia. Lisboa: Climepsi Editores, 2001.

FREIRE, Paulo. Pedagogia da autonomia: saberes necessários à prática educativa. São Paulo: Paz e Terra, 1996.

FRIEDERICI, Angela D.; WEISSENBORN, Jürgen. Mapping sentence form onto meaning: The syntaxsemantic interface. Brain Research, v.1146, p. 50-58, 2007.

GAZZANIGA, Michael; HEATHERTON, Todd; HALPERN, Diane. Ciência psicológica. 5.ed. Tradução de Maiza Ritomy, Sandra Maria Mallmann da Rosa e Soraya Imon de Oliveira. Porto Alegre: Artmed, 2018.

HEINIG, Otilia Lizete Martins de Oliveira. O papel do professor no processo da construção de sentido na leitura. In: SOUZA, Ana Cláudia de; SEIMETZ-RODRIGUES, Cristiane; FINGERKRATOCHVIL, Claudia; BARETTA, Luciane; BACK, Angela Cristina Di Palma. (org.). Diálogos linguísticos para a leitura e a escrita. Florianópolis: Insular, 2019. p. 107-129.

HOCHBERG, Joe. Perception. 2 ed. New Jersey: Prentice-Hall, Inc., 1978.

KLEIMAN, Angela. Texto e leitor: aspectos cognitivos da leitura. Campinas: Editora da UNICAMP, 1989.

KLEIMAN, Angela. Oficina de leitura: teoria e prática. 9. ed. Campinas, SP: Pontes, 2002.

$\mathrm{KOCH}$, Ingedore Villaça. O texto e a construção dos sentidos. 10. ed. São Paulo: Contexto, 2011.

LAJOLO, Marisa; ZILBERMAN, Regina. A formação da leitura no Brasil. São Paulo: Ática, 1996.

LEIBNIZ, Gottfried Wilhelm. Discurso de Metafísica. (DM). In: LEIBNIZ, G. W. Discurso de metafísica e outros textos. São Paulo: Martins Fontes, 2004.

LEONTIEV, Alexei. O desenvolvimento do psiquismo. Lisboa: Livros Horizonte, 1978.

\footnotetext{
${ }^{5}$ Justificamos a opção pelos nomes completos dos autores como uma opção política que visa dar visibilidade à mulher e ao seu papel na ciência.
} 
LOPES, Milton, da Costa. Dificuldades de aprendizagem escolar na mestria do código escrito: teste de avaliação da compreensão. Coleção Horizontes Pedagógicos. Lisboa: Instituto Piaget. 2008.

MARTINS, Margarida Alves; NIZA, Ivone. Psicologia da aprendizagem da linguagem escrita. Lisboa: Universidade Aberta, 1998.

MORAIS, José. Alfabetizar para a democracia. Porto Alegre: Penso, 2014.

MORAIS, José; KOLINSKY, Regine. Psicolinguística e leitura. In: MAIA, Marcus (org.). Psicolinguística, psicolinguísticas: uma introdução. São Paulo: Contexto, 2015. p 129-141.

ORLANDI, Eni Pulcinelli. O inteligível, o interpretável e o compreensível. In: ZILBERMAN, Regina, SILVA. Ezequiel Theodoro (org.). Leitura: perspectivas interdisciplinares. São Paulo: Ática, 1988.

REBELO, José Augusto da Silva. Dificuldades da leitura e escrita em alunos do ensino básico. 1991. Tese. (Doutorado em Ciências da Educação) - Orientador: SIMÕES, António. Universidade de Coimbra. Coimbra, 1991.

ROCK, Irvin. An Introduction to perception. New York: Macmillan Publishing, 1975.

RODRIGUES Ana Patrícia Inácio. Processos cognitivos e leitura: estudo comparativo em crianças com e sem dificuldades na leitura. Lisboa: ISEC, 2012.

ROJO, Roxane. Letramentos múltiplos, escola e inclusão social. São Paulo: Parábola Editorial, 2009.

RUDELL, Robert. B., UNRAU, Norman. J. Reading as a meaning-construction process: the reader, the text, and the teacher. In: SINGER, Harry, RUDELL, Robert. B. (ed.). Theoretical model and processes of reading. Newark: IRA, 1994.

SALVADOR, César Coll. Aprendizagem escolar e construção do conhecimento. Tradução de Emília de Oliveira Dihel. Porto Alegre: Artes Médicas. 1994.

SEKULER, Robert; BLAKE, Randolph. Perception. 2. ed. New York: McGraw-Hill, Inc., 1990.

SIMOES, Fátima; RODRIGUES, Leonor; ESGALHADO, Graça; GUIMARAES, Carina. Desenvolvimento do autoconceito pela tutoria pedagógica por crianças do primeiro ciclo. Rev. Semestral Assoc. Bras. Psicologia Escolar Educacional (ABRAPEE), v.12, n.2, p. 327-336, 2008.

SOUZA, Ana Cláudia de; GARCIA, Wladimir Antônio da Costa. A produção de sentidos e o leitor: os caminhos da memória. Florianópolis: 1. ed. NUP/CED/UFSC, 2012.

SOUZA, Ana Cláudia de; WEIRICH, Helena Cristina; PROCAILO, Leonilda. A compreensão da argumentação linguística: hipótese de interação entre leitura e oralidade. Revista de Estudos da Linguagem, v.25, n.2, p.873-901, 2017.

SOUZA, Ana Cláudia de; SEIMETZ-RODRIGUES, Cristiane; WEIRICH, Helena Cristina. Ensinar a estudar ensinando a ler: potências dos roteiros de leitura. In: SOUZA, Ana Cláudia de; SEIMETZRODRIGUES, Cristiane; FINGER-KRATOCHVIL, Claudia; BARETTA, Luciane; BACK, Angela Cristina Di Palma (org.). Diálogos linguísticos para a leitura e a escrita. Florianópolis: Insular, 2019. p. 164200.

TONELOTTO, Josiane Maria de Freitas. Atenção e sua relação com atitudes de crianças no contexto escolar. 1998. Tese (Doutorado em Ciências Médicas/Neurologia) - Orientadora: Vanda Maria Gimenes Gonçalves. Universidade Estadual de Campinas - UNICAMP. Campinas, São Paulo, 1998. 
TONELOTTO Josiane Maria de Freitas; GONÇALVES, Vanda Maria Gimenes. Autopercepção de crianças desatentas no ambiente escolar. Rev. Estudos de Psicologia, PUC-Campinas, v.19, n.3, p.31-41, setembro/dezembro 2002.

VIANA, Fernanda Leopoldina; TEIXEIRA, Maria Margarida - "Aprender a ler: da aprendizagem informal à aprendizagem formal". Porto: Edições ASA, 2002

VIGOTSKI, Lev Semyonovich. A formação social da mente: o desenvolvimento dos processos psicológicos superiores. 6 ed. São Paulo: Martins Fontes, 1998.

VIGOTSKY, Lev Semyonovich. Pensamento e linguagem. 6 ed. São Paulo: Martins Fontes, 1993. 